\title{
ARTGO ORIGINAL \\ Honra ao mérito: como a instituição do Prêmio Esso contribuiu para a adoção dos referenciais de objetividade jornalística no Brasil
}

Honor and Merit: Esso Prize institution and its contribution to the adoption OF JOURNALISTIC OBJECTIVITY BENCHMARKS IN BRAZIL

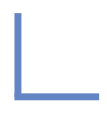

\section{Robson Dias}

Doutor em Comunicação, pela Universidade de Brasília (Programa de Pós-Graduação da Faculdade de Comunicação, PPGFAC/UnB), Professor titular do mestrado Stricto Sensu em Comunicação da Universidade Católica de Brasília (PPGSSCOM/UCB).r.ucbprofessor@, gmail.com

Recebido em 29 de outubro de 2013. Aprovado em 14 de fevereiro de 2014

\section{Resumo}

Os prêmios são dispositivos que prescrevem ethos, valores e procedimentos aos profissionais de Jornalismo. E tendem a fomentar um dado modelo jornalístico. No caso do Brasil, o Prêmio Esso serviu de fomento ao Jornalismo Informativo (isenção, imparcialidade, impessoalidade) e ao Jornalismo Investigativo (denúncia). A abordagem traz o processo histórico de adoção dos critérios de objetividade na imprensa brasileira a partir do Prêmio Esso com a instauração de uma meritocracia própria em dispor sobre o que era (ou não) jornalismo profissional no país. O artigo é fruto de uma tese de doutorado em Comunicação, pesquisa histórica e - documental, em âmbito nacional.

Palavras-chave: Jornalista, Objetividade, Prêmio Esso.

\section{Abstract}

Prizes are devices that prescribe ethos, values and procedures to journalists. And they tend to foster a given journalism model. In the Brazilian context, the Esso Prize have promotinged the Informative Journalism News (detachment, impartiality, neutrality) and the Investigative Journalism (report). The approach brings the historical process of adoption of the criteria of objectivity in the Brazilian press from the Esso Prize with the establishment of an own meritocracy to dispose of what was (or not) professional journalism in the country. The article is based on a doctoral thesis in Communication, of historical research and - documentation, nationwide.

Keywords: Journalist, Objectivity, Esso Prize. 


\section{Introdução}

Os prêmios em Jornalismo figuram como elementos de normatividade e prescrição de ethos, valores e procedimentos na cultura profissional jornalística. As organizações que editam premiações podem ser entendidas como definidores primários não somente no processo de produção da notícia e nas rotinas produtivas (modo direto), mas também das chancelas de mérito jornalístico por meio dos prêmios na cultura profissional (modo indireto), influenciando o jornalista na questão do que é ou não notícia (news judgement) (Tuchman, 1993, p. 85). A partir da certificação premiativa, que prescreve o "profissionalismo" como "método de controle do trabalho" (Traquina, 2001, p. 107), dando o status de bom ou mau jornalismo, há o explícito reconhecimento do domínio das técnicas do fazer, além do saber, como procedimento jornalístico. Mas, tacitamente, também há a doutrinação da subjetividade dos jornalistas.

Frequentemente, nos estudos de Agendamento e Newsmaking, fala-se muito de como os definidores primários (HALL et al., 1993) agem em relação às rotinas produtivas (TuCHMAn, 1993) no cotidiano profissional, mas não se comenta muito sobre as rotinas cognitivas (SOUSA, 2003) ou limites cognitivos (TRAQUINA, 1993) relativos à subjetividade de cada jornalista. O que valida não apenas o doutrinamento da pauta das redações (rotinas produtivas), mas a cosmovisão dos jornalistas (rotinas cognitivas).

As organizações tendem a influenciar diretamente o processo de produção da notícia (Molotch \& Lester, 1974) e as rotinas produtivas (Tuchman, 1978), mas também influenciam indiretamente ao apontar para a subjetividade do indivíduo (cosmovisão do jornalista) na cultura profissional (SCHUDSON, 1993; HALL et al., 1993).

Diante deste quadro conceitual, tem-se que a cultura profissional é um complexo emaranhado de retóricas de fachada e astúcias táticas, de códigos, de estereótipos, de símbolos, de tipificações latentes, de representações de papéis, rituais e convenções, relativos às funções dos mass media e dos jornalistas na sociedade, à convenção do produto-notícia e às modalidades que superintendem sua confecção (WOLF, 2001, p. 189). Sendo que o profissionalismo controla o comportamento dos jornalistas de dois modos relacionados: estabelecendo padrões de conduta e normas de comportamentos (1); e determinando o sistema de recompensa profissional (2) (SoLOSKI, 1993, p. 95).

O primeiro aspecto, dos padrões de conduta e normas de comportamentos, é relativo à atuação indireta dos definidores primários frente a dissonâncias cognitivamente induzidas nos jornalistas em suas redações e rotinas produtivas. Dentro do cotidiano de produção da notícia de cada profissional, existem as rotinas cognitivas: percepções que o jornalista tem da realidade, podendo, posteriormente, favorecer a avaliação do que é

$124 \frac{\text { Comunicação \& Inovação, PPGCOM/USCS }}{\text { v. 15, n. } 29 \text { (126-137) jul-dez } 2014}$ 
Honra ao mérito: como a instituição do Prêmio Esso contribuiu para a adoção...

noticioso, além do fato das rotinas produtivas estarem confinadas nos limites cognitivos da racionalidade (ibid., p. 93).

E o segundo aspecto, sobre o sistema de recompensa profissional, trata da questão do prêmio como substantivo, no sentido dicionarizado: recompensa, bônus, agrado, galardão, ou seja, aquilo que se ganha (simbólica ou materialmente) ao chegar a um objetivo.

Como justificativa ao objeto da reflexão, dentro desta breve contextualização no âmbito das práticas e dos estudos jornalísticos, este artigo tem como objetivo apresentar os aspectos históricos relativos ao Prêmio Esso em relação a diversos conceitos identificados em Teorias da Comunicação, tais como: controle do seu trabalho (BREED, 1993) nas rotinas produtivas (TuCHMAN, 1993), a questão da ação pessoal e seleção de notícias (Lewin, 1993) por um filtro (White, Senra, 1993), o profissionalismo (Soloski, 1993), sofrimento com a pressão do tempo (SCHLESINGER, 1993), relacionamento entre fontes e os jornalistas (Molotch \& Lester, 1993), além de questões relativas à visão de mundo e cultura profissional (Schudson, Hall et al. , 1993). Sempre em relação a modelos jornalísticos que fomentaram os critérios de objetividade jornalística, tendo em vista quase 60 anos de edição do Prêmio Esso no Brasil e a inviabilidade de tratar densamente de cada período no formato artigo.

No curso do artigo, entende-se que um modelo seja um conceito de valores e práticas padrão hegemônico. Diferentemente de modalidade, relativo a um padrão alternativo, orbital, em dado sistema, com vistas a se tornar central. Estas são as duas categorias com as quais abordaremos esse grande período de 60 anos que o Prêmio Esso atravessa no jornalismo brasileiro. O contexto dos prêmios está cravejado por zonas nas quais modelos e modalidades de jornalistas marcam território e descrevem o que é (ou não) jornalismo. Alguns, de forma determinante. Outros, de modo flexibilizante. O Jornalismo Informativo e o Jornalismo Investigativo, a partir da adoção dos critérios de objetividade, puxaram para a si o "domínio" do que é referendado como sendo jornalismo profissional. Essa ideia e todo o seu determinismo teve efeitos sobre a atividade jornalística, sendo compartilhada pela sociedade.

Inicialmente, o mercado noticioso foi criado com a anulação do sujeito no jornalismo, como mecanismo de afirmação do cientificismo e do status de verdade na profissão. A objetividade também deu o limite profissional entre redações e assessorias. Com o passar do tempo, algumas práticas emergiram dentro deste contexto pós-objetividade, retomando o sujeito: o Novo Jornalismo (retomando a questão do sujeito na narrativa) e o Jornalismo Público (retomando o sujeito como interventor da realidade), que são modalidades flexibilizantes (padrão alternativo) ao modelo determinista da isenção, impessoalidade e imparcialidade (padrão hegemônico). 
O Prêmio Esso, inicialmente, era bem prescritivo com este aparato relativo à adoção dos critérios de objetividade (isenção, imparcialidade, anulação do sujeito, valorização da função do repórter, separação dos conteúdos noticiosos entre informação e opinião, além de ênfase no Jornalismo Investigativo). O próprio código de ética, no Brasil, também tinha essa configuração: como o Código de Ética dos Jornalistas Profissionais (1987), do período de estruturação da profissão no país. Recentemente, a edição do Código de Ética dos Jornalistas Brasileiros (2007) tem um texto voltado para uma nova perspectiva de jornalismo de atuação social, em vista de um processo já estabelecido de profissionalização da atividade. E se difere em vários pontos da ênfase, pois o novo código já tem dispositivos que consideram os jornalistas nas organizações e não só nas redações (flexibilidade).

Recentemente, algumas pesquisas têm demonstrado que a tipologia de Jornalismo Investigativo tem sofrido interferência de interações com outros atores sociais, além da ampliação do significado e meios pelos quais são produzidas as notícias: Silva (2003, 2006, 2007), Magno (2006), Nascimento (2007), Oliveira (2008) e Mora (2008).

Magno (2006) já tinha notado mudanças significantes, a partir do Prêmio Esso, na tipologia de Jornalismo Investigativo, em 51 anos (1955-2006). Para a autora, não há mais reportagens sociais, a julgar pelos vencedores do gênero reportagem estudado por ela em cinco décadas. Magno acredita que o marco final dessa prática pode ser estabelecido na cobertura sobre o assassinato de Chico Mendes, em 1989, que teve matéria ganhadora na principal categoria da profissão, mas também sendo a última grande reportagem de cunho social. Em sua pesquisa, ela demonstra que apenas quatro exceções não se enquadram neste diagnóstico. Sendo a ênfase das reportagens premiadas pelo Prêmio Esso (ou o "único tema premiado na categoria principal”) a corrupção política no Legislativo, no Executivo e no Judiciário (concentrada em São Paulo, Rio e Brasília). A autora trabalha a questão de a reportagem ter se especificado no país como um gênero tipicamente denuncista.

Nascimento (2007) amplia essa perspectiva denuncista ao tratar da cobertura de eleições entre 1989 e 2002. O autor percebe o seguinte: o que se julga ser a tipologia de Jornalismo Investigativo (resultado de investigação feita pelo próprio jornalista) se mostrou ser Jornalismo sobre Investigações, dedicado a divulgar informações de investigações feitas por autoridades oficiais (polícia e ministério público). A análise levava em conta as três maiores revistas semanais de informação do país: Época, IstoÉ e Veja, e a dependência do Jornalismo Investigativo das fontes institucionais, fazendo que essa tipologia se alimentasse da informação gerada no ambiente organizacional.

$126 \frac{\text { Comunicação \& Inovação, PPGCOM/USCS }}{\text { v. 15, n. } 29 \text { (126-137) jul-dez } 2014}$ 
Honra ao mérito: como a instituição do Prêmio Esso contribuiu para a adoção...

Depois dessa breve introdução sobre tensões relativas a prêmios, modelos, modalidades e tipologias jornalísticas, segue o resgate sobre as origens do Prêmio Esso e sua relação com a adoção (ou não) dos critérios de objetividade no Brasil a partir de estudiosos desta premiação: Cassol (1997), Magno (2006), Passos (2007) e Castilho (2010).

\section{Cultura meritocrática premiativa dentro da cultura profissional}

Na década de 1950, foram adotados pela imprensa brasileira preceitos de linguagem e de forma jornalística, tais como: estilo direto, imparcialidade, factualidade, isenção, neutralidade, distanciamento, copy-desk, manuais de redação, além das técnicas de lead e pirâmide invertida. Esse preceitos foram trazidos principalmente pelos jornalistas Pompeu de Souza, Danton Jobim e Luiz Paulistano.

O Prêmio Esso de Jornalismo, como o mais tradicional e consagrado da imprensa brasileira e grande instaurador deste deste paradigma de certificação de "bom procedimento" jornalístico por meio de premiações, na década de 1950, é um divisor de águas também entre o dito "profissional" e o amador (exatamente por fomentar o modelo de Jornalismo Informativo, em detrimento do Jornalismo Literário), informação e opinião (pelos mesmos modelos), além da separação entre redações e assessorias (com o Jornalismo Investigativo munido da denúncia, em detrimento do Jornalismo Empresarial, posteriormente chamado de Jornalismo Institucional, munido da promoção). A configuração de um mercado noticioso brasileiro e da adoção de novos formatos e gêneros jornalísticos como produtos (notícia, reportagem investigativa) está ligada a uma questão histórica de importação de um modelo, um modus operandi, de como se fazer jornalismo, vindo dos EUA. Tanto a cultura profissional (a partir de um modelo), assim como a cultura meritocrática premiativa (a partir de um prêmio fomentador deste modelo em questão) vêm de terras estrangeiras.

\section{Cultura profissional a partir da objetividade}

A expansão capitalista, no período de industrialização do século XIX, vinculou a atividade jornalística à circulação de bens e mercadorias. Com o impacto tecnológico e comercial, a imprensa passou por uma estruturação e sistematização em conformidade com o trânsito de mercadorias e o consumo de informação, nos Estados Unidos e em alguns países da Europa. Segundo Mariani (2007), os parques gráficos de editoras e jornais foram revisitados e o processo de produção de notícias passou por uma adequação da linha de produção. Surgiu, assim, um contexto industrial e a lógica de um mercado 
noticioso. Nesse processo, houve padronização de uma série de procedimentos nas redações, como o impacto na divisão do trabalho (fordismo), a nova rotina operacional - e a tematização dos assuntos em editorias e gêneros textuais.

As corporações que exploravam o mercado de informação, em Jornalismo, mais especificamente da imprensa, criaram Manuais de Redação e Manuais de Redação e Estilo no sentido de codificar parâmetros e formatos nos quais deveria basear-se a produção dos produtos noticiosos. Sendo que este manuais já representavam uma prescrição de ethos intra-organizacional, posteriormente expandida por cartilhas e manuais de redação extra-organizacionais entregues nas redações pelos assessores, como medida e sugestão de como tratar dado assunto.

Antes da adoção dos critérios de objetividade, a imprensa tinha como paradigma um jornalismo inspirado na literatura: o Jornalismo Literário. Com a adoção dos pressupostos da objetividade pelos jornalistas, este paradigma passou a ser considerado como superado, pois tinha como base dos relatos a opinião. Em vista disso, era considerado panfletário e partidário.

A padronização do novo modo de exercer a atividade jornalística, institucionalizada no Jornalismo, já como profissão e mercado noticioso, consolidou um formato no qual a anulação do sujeito (isenção, imparcialidade e impessoalidade) se tornava inerente à notícia. Em suma, a técnica que antes era vista como arte de escrever (Jornalismo Literário) se transformou em ferramenta de produção (Jornalismo Informativo).

O contexto industrial no qual se instalou o Jornalismo Informativo contribuiu para a organização positivista das matérias jornalísticas. A racionalidade moderna, aliada ao cientificismo cartesiano e positivista, foi incorporada ao modus operandi da imprensa incorrendo na consolidação de um novo arcabouço de técnicas jornalísticas.

A maior influência do Jornalismo Informativo sobre a atividade jornalística e a imprensa foi em relação à validação do que é verídico (fatos) e verdadeiro (discurso) nos relatos noticiosos. A racionalidade serviu para trazer um status cartesiano de "verdade verificada" e de "método de apuração ao Jornalismo". Tal fato contribuiu para que o campo se tornasse um poderoso constituidor de realidades e sentidos, em uma sociedade em que quase todo esse direito era reservado à ciência (SANTANA, 2001. p. 141).

Os pressupostos de objetividade funcionam como um divisor de águas no Jornalismo. A partir do acatamento dos referenciais objetivos pela imprensa, o campo jornalístico passou a se estruturar na representação social de que o lugar de fala, em Jornalismo, é baseado na verdade: longe da cultura, do social, da política e da ideologia. Tal mudança de paradigma conferiu isenção ao discurso jornalístico, como um olhar

$128 \frac{\text { Comunicação \& Inovação, PPGCOM/USCS }}{\text { v. 15, n. } 29 \text { (126-137) jul-dez } 2014}$ 
Honra ao mérito: como a instituição do Prêmio Esso contribuiu para a adoção...

externo, referenciado em um lugar antes ocupado somente pela ciência (era Moderna) e pelo transcendente (era Medieval).

Armony (2006, p. 24) considera que a influência do Jornalismo Informativo gerou uma demanda de coesão social e orgulho ocupacional, além de um controle interno da atividade jornalística, ao mesmo tempo em que a política se tornava mais organizada. Para o autor, tal fato ajudou a empurrar o Jornalismo para fora do partidarismo, tornando-o uma força externa em vez de ser um mero instrumento de cabos eleitorais. Para o autor, os pressupostos de objetividade emergiram no campo jornalístico como forma dos editores manterem controle sobre os repórteres que trabalhavam na redação. Com isso, cristalizou-se um novo ethos para o campo, que se estabeleceu como padrão, dentro da categoria profissional.

Os efeitos internos (normatização do grupo) e externos (ideia de isenção, imparcialidade e impessoalidade) explicam também a condição histórica da criação e desenvolvimento da profissão de Relações Públicas (RP). A influência do paradigma relacionado à objetividade foi tão forte nos EUA que a atividade de RP foi criada como consequência da demarcação clara, na imprensa, do que é informação, publicidade e comunicação corporativa.

\section{Cultura meritocrática a partir de prêmios internacionais}

Os prêmios internacionais servem de inspiração e modelo para os que foram editados no Brasil. O Prêmio Pulitzer (1917), "o mais importante" prêmio jornalístico dos EUA (e "o mais famoso" do mundo) (NAscimento, 2007, p. 40), foi criado em homenagem ao jornalista Joseph Pulitzer, fundador do curso de Jornalismo da Universidade de Columbia (1912), em Nova York. O prêmio (1), o curso (2), assim como o próprio Joseph Pulitzer (3), foram atores importantes no processo de profissionalização do jornalismo norte-americano. Todo esse aparato visava a ruptura com o contexto anterior do Jornalismo em zonas limítrofes à literatura e às Relações Públicas. O prêmio é o mais tradicional dos EUA e tem muita credibilidade, o que ocasionou até a devolução de algumas premiações.

A Columbia University Graduate School of Journalism não é, a rigor, o primeiro curso a ser editado nos EUA. Já em 1869, como demanda de estratégia militar, foi fundada a Washington College, na Virgínia, pelo general Robert E. Lee. Posteriormente, outras escolas surgiram com o mesmo intuito. Era uma formação para uso estatal (militar). Na pesquisa, atrelamos a edição ao uso comercial, mercantil, vinculado também à profissionalização da atividade jornalística, além do mercado de imprensa. 
O Prêmio Pullitzer é tido como o mais tradicional internacionalmente, não apenas nos EUA. Por mais que seja inspiração para o Prêmio Esso, no Brasil, não o abordamos em vista da configuração do jornalismo brasileiro de, a partir dos anos 1980, os jornalistas também ocuparem postos de trabalho nas assessorias de imprensa.

O interessante, aqui, é vislumbrar como efeito da adoção dos critérios de objetividade, como efeito posteriores: a instauração de um prêmio com certificação de dado padrão em Jornalismo (1), com posterior instauração de cursos de formação acadêmica ou corporativa (2), a edição de códigos de conduta (como o código de ética compartilhado pela categoria profissional), Manuais de Redação e Estilo (intra-organizacionais) (3), nova divisão do trabalho a partir da profissionalização da atividade jornalística, separando-a da literatura e das Relações Públicas (4), e criação de gêneros jornalísticos (separação entre informação e opinião) (5). Veremos mais à frente que, no Brasil, o Prêmio Esso também se insere em um contexto parecido. Tanto que autores chegam a declará-lo como “nosso Pulitzer" (Magno, 2006, p. 74).

\section{Cultura Profissional, no Brasil, a partir da objetividade}

Os critérios relativos à objetividade chegaram ao Brasil nos anos 1950. Vieram junto com o pacote de técnicas jornalísticas importadas dos EUA pelo Diário Carioca.

Durante duas décadas (anos 1950 e 1960), houve a imposição de um padrão prosélito do que se chamava de Jornalismo Profissional, assim como aconteceu em outros países. Três personagens estiveram diretamente envolvidos: Danton Jobim, Pompeu de Souza e Luiz Paulistano. O modus operandi das redações no país ainda era baseado apenas no referencial de Jornalismo Literário. Os pressupostos de objetividade foram literalmente importados dos EUA e patrocinados pelo governo brasileiro em um intercâmbio entre os países.

O padrão de Jornalismo Informativo foi lançado pelo Diário Carioca (anos 1950) e fixado na famosa revolução editorial do Jornal do Brasil (anos 1960), período que coincide com a volta dos jornalistas do intercâmbio nos EUA. Mais tarde, o paradigma se tornou hegemônico e assimilado por $O$ Globo, Folha de S. Paulo e O Estado de S. Paulo (nos anos 1970).

Apesar de não ser um conceito ou uma técnica propriamente dita, a importância do referencial de objetividade é tão perceptível que chega a ser verificada em levantamentos feitos em livros de formação acadêmica de jornalistas. Hohlfeldt (2001) pesquisou em 21 livros de jornalismo os principais critérios utilizados para a construção de um texto jornalístico. O material, em sua maioria, era de autores e pesquisadores brasileiros (equivalente a $76 \%$ da amostra). A análise levou o autor a considerar a objetividade como a

$130 \frac{\text { Comunicação \& Inovação, PPGCOM/USCS }}{\text { v. 15, n. } 29 \text { (126-137) jul-dez } 2014}$ 
Honra ao mérito: como a instituição do Prêmio Esso contribuiu para a adoção...

categoria jornalística mais citada. Na amostra, o termo perdia em referências apenas para os verbetes: "exatidão" e "precisão".

\section{Cultura Meritocrática, no Brasil, a partir do Prêmio Esso}

O Prêmio Esso de Reportagem, depois rebatizado de Prêmio Esso de Jornalismo, é o "mais tradicional" da imprensa brasileira. Foi editado no país pela multinacional Standard Oil Company of Brazil, braço da petrolífera Standard Oil Trust, do grupo americano Rockfeller. Aliás, as iniciais desta organização, pronunciadas em inglês ("S" e "O”), dão o nome de batismo, em português, à empresa Esso (oficialmente: Esso Standard do Brasil).

Já instalada no Brasil, a empresa estava inserida em um contexto político nacionalista da política de exploração e distribuição de recursos chamada "o Petróleo é nosso", durante o governo Getúlio Vargas (Estado Novo). Nesse período, teve foco em estratégias de Comunicação.

A partir dos anos 1940, a Esso dirige seus esforços para o campo da comunicação com o intuito de reforçar a divulgação dos seus produtos. Três ações podem ser destacadas na aproximação da multinacional com a comunidade jornalística: a criação do programa radiofônico Repórter Esso, posteriormente transmitido na televisão, o investimento publicitário em jornais e revistas e a implantação em 1956 do Prêmio Esso de Jornalismo, um dos mais importantes programas institucionais da companhia no Brasil. (...) A Esso também viria a patrocinar nos anos $1950 \mathrm{o}$ programa "Honra ao mérito", veiculado na Rádio Nacional (CASTILHO, 2010, p. 23 - 24).

Assim como o Prêmio Pulitzer, o Prêmio Esso fez parte de um contexto de profissionalização da atividade jornalística, trazendo um aspecto mais empresarial e mercadológico para as tiragens das edições, assim como na produção dos produtos noticiosos. Nesse cenário, era emergente a renovação do parque gráfico (tecnologia de impressão), a concepção gráfica e editorial, a delimitação do espaço discursivo (informação e opinião), a divisão do trabalho delimitação dos espaços específicos entre profissões (Relações Públicas e Jornalismo), além da questão relativa ao sujeito (isenção, impessoalidade e imparcialidade) e à narrativa (informação separada da opinião). Sem falar nos cursos corporativos de formação (seminários) e a figura do aprendiz nas redações (estágio):

Localizamos outras ações de relações públicas empreendidas pela multinacional: o Seminário Esso de Jornalismo, objetivando o aperfeiçoamento profissional dos produtores de notícias, o 
Programa de Estágio para Jornalistas, que buscava trazer jornalistas do interior para conhecer o processo de produção jornalística nos veículos mais importantes do Rio e de São Paulo, e o Prêmio de Literatura Esso, em parceria com o Jornal de Letras. Voltado para universitários, o concurso literário apresentava as categorias de conto e ensaio, além da distribuição de menções honrosas. O prêmio incluía uma quantia em dinheiro e um curso de férias de língua e literatura portuguesa na Universidade de Lisboa (CASTILHO, 2010, p. 27).

Neste período, havia um esforço do governo Getúlio Vargas em monopolizar a exploração e distribuição do petróleo, o que ia contra os interesses do grupo norte-americano, Esso Standard do Brasil. As estratégias de Comunicação, no país, não foram benevolências para melhorar o Jornalismo gratuitamente, mas investidas para ganho de espaço do discurso oposto ao nacionalismo do Estado Novo na mídia brasileira (ao menos quanto ao monopólio da exploração).

Ao valorizar a profissão de jornalista, dar ênfase na função de repórter e desenvolver o mercado da imprensa (na perspectiva do Jornalismo Informativo e Jornalismo Investigativo), o Prêmio Esso sensibilizou os jornalistas para suas demandas institucionais, além de darem a versão da Standard Oil of Brazil de que o petróleo não era somente do Brasil (se opondo à política nacionalista de Vargas), mas também dos norte-americanos.

Pode parecer que o Prêmio Esso seja um prêmio de redações para redações: jornalistas profissionais para jornalistas profissionais. No entanto, o Prêmio Esso nada mais é (e foi) do que uma estratégia organizacional de agendamento do noticiário, bem aos moldes do Jornalismo Institucional. Os prêmios, em geral, constroem a constelação dos olimpianos do Jornalismo, além de fomentarem uma categoria mítica na profissão como referencial de prática exemplar.

No contexto da imprensa, a anuência ao Prêmio Esso veio da Associação Brasileira de Imprensa $(\mathrm{ABI})$, que apoiava o prêmio por prescrever valores relativos à objetividade e ainda indicava jornalistas para participar dos juris. O prêmio realmente desenvolvia a profissão e o mercado.

O governo Getúlio Vargas entendia que os jornalistas brasileiros precisam dos referenciais de objetividade para se afastar da opinião e não ser um entrave para o Regime Militar. Tanto que foram firmados intercâmbios para capacitar jornalistas:

Ele começou a trabalhar como jornalista na década de 40, período que os Estados Unidos intensificaram o incentivar ao programa de intercâmbio cultural entre os dois países, com o aval do Departamento de Imprensa e Propaganda (DIP), criado em 1939 por Getúlio Vargas, que administrava o País sob a égide do Estado Novo. No cenário internacional, a Segunda Guerra Mundial fervilhava em terras européias. Produzindo notícias para o rádio - Pompeu de Sousa foi

$132 \frac{\text { Comunicação \& Inovação, PPGCOM/USCS }}{\text { v. 15, n. } 29 \text { (126-137) jul-dez } 2014}$ 
Honra ao mérito: como a instituição do Prêmio Esso contribuiu para a adoção...

para os EUA indicado pelo DIP, onde permaneceu durante 22 meses. Neste período trabalhou nas rádios NBC (National Broadcasting Company) e CBS (Columbia Broadcasting System). A NBC estava instalada no prédio do Rockefeller Center e a CBS foi a primeira a ampliar o setor radiofônico acompanhando a política de boa vizinhança dos Estados Unidos para com a América Latina (MeNDEZ, 2006, p. 4).

Pompeu de Sousa, para muito além de qualquer estratégia do Prêmio Esso, já tinha relações com braços administrados pelos Rockfeller, no caso a Columbia Broadcast Station (jornalismo da CBS), por uma demanda governamental. O interessante deste cenário é perceber que a objetividade era um preceito adotado e promovido pelo governo de Getúlio Vargas a ser adotado pela imprensa nacional. Mas, ironicamente, outro braço do grupo Rockfeller era inconveniente: a Esso Standard do Brasil se posicionar contra o nacionalismo de "o petróleo é nosso". Em suma, a tensão entre o Brasil e os norte-americanos era: o Brasil se interessava muito pelo Jornalismo Informativo (imprensa), mas repudiava a perda de soberania na questão petrolífera (energia). Politicamente, a direita defendia a abertura na Comunicação e Energia. E a esquerda era contra, tomando um discurso nacionalista.

A presença do capital estrangeiro na imprensa por meio da publicidade provocou intenso debate no campo jornalístico e nos meios políticos. A divisão de opiniões refletia a própria conjuntura do pós-guerra, com o acirramento da disputa entre pólos distintos. De um lado, os grupos mais liberais, que defendiam a abertura de mercado e viam na publicidade uma possibilidade de autonomia dos jornais em relação ao poder político. Do outro, os que assumiam um discurso nacionalista, com orientação mais próxima do pensamento da esquerda. Para estes opositores, a publicidade servia como instrumento de controle dos jornais, pois interferia diretamente no noticiário, representando uma ameaça à liberdade de imprensa no país. Alegavam que a participação das empresas e agências estrangeiras no mercado jornalístico era uma tentativa de desnacionalização da imprensa (CASTILHO, 2008, p. 7).

Além do mercado petrolífero e o noticioso, a Esso Standard do Brasil passou a demonstrar outra influência: a força no mercado publicitário. Na CPI instalada em 1957, a questão do petróleo foi apontada como determinante para o aumento da participação do capital estrangeiro na imprensa brasileira.

A conclusão da CPI sobre o mercado petrolífero no Brasil confirmava o poder de companhias estrangeiras no mercado de petróleo no Brasil. Os deputados observaram que, apesar de o artigo 160 da Constituição Federal proibir participação acionária de grupos estrangeiros em veículos de 
comunicação no país, o mesmo não ocorria com as agências de publicidade. Estas trabalhavam a serviço das multinacionais, exercendo, segundo a comissão, influência indireta [Publicidade] no conteúdo noticioso (CASTILHO, 2010, p. 40).

A influência indireta da Esso Standard do Brasil era percebida no mercado noticioso, via publicidade. Já, de forma direta, fruto de esforço organizacional, gestado por Ney Peixoto do Valle, o Prêmio Esso era uma medida de relacionamento direto da empresa com os jornalistas e formadores de opinião (num aspecto mais amplo).

Segundo Castilho (2007, pp. 69-70), a primeira edição teve a inscrição de apenas 200 trabalhos. Na segunda edição, o prêmio cresceu em inscrições e até expandiu seu escopo nas categorias regionais sul e norte/nordeste, além de instituir a menção honrosa. Na terceira edição, abriu a categoria regional: centro-oeste. A cada edição, a premiação incorporava novas medidas em edital: destaques especiais, votos de louvor. A premiação que começou com o nome de Prêmio Esso de Reportagem passou a ser denominado Prêmio Esso de Jornalismo, em consonância com o desenvolvimento da imprensa no país. Para o autor, com o crescimento do Fotojornalismo na imprensa brasileira, a premiação logo se adequou a este cenário ao criar, em 1961, a categoria fotografia.

O prestígio alcançado pelo Prêmio Esso se confunde com o processo de profissionalização da atividade jornalística no Brasil. Um fenômeno semelhante ao que também ocorreu nos EUA, em relação ao Prêmio Pulitzer.

A formação de um ideal do jornalista como observador neutro, que privilegia fatos em detrimento de opiniões, emerge inicialmente em meados do século XIX, quando os proprietários de jornais nos Estados Unidos começam a explorar a informação como fonte geradora de lucro e não apenas como capital político. Nos anos 20 , consolida-se naquele país a objetividade como valor importante na construção de notícias. Mais do que reafirmar uma fé nos fatos, ou seja, a notícia como simples espelho da realidade, os jornalistas defendiam a objetividade principalmente como método para se preservar da eficácia da propaganda durante a Primeira Guerra Mundial (CASTILHO, 2007, p. 46).

O referencial de objetividade como preceito do Jornalismo Informativo tem grande influência em vários aspectos em relação aos prêmios. É importante notar que nos EUA, assim como no Brasil, a emergência desta modalidade de Jornalismo culminou no processo de edição de prêmios com os preceitos de um modelo de jornalismo noticioso e profissional (1), a emergência de cursos corporativos e acadêmicos de formação de 
Honra ao mérito: como a instituição do Prêmio Esso contribuiu para a adoção...

repórteres (2), ao dito profissionalismo da atividade jornalística em contraste com a produção literária, opinativa e organizacional (3).

Inspirado no Prêmio Pulitzer, principal prêmio de jornalismo americano, o Prêmio Esso foi criado e adaptado à realidade brasileira. De 1955 a 2012, concorreram ao Prêmio Esso mais de 28 mil trabalhos jornalísticos, em mais de 20 categorias. A premiação é tradicionalmente de mídia impressa, mas tem categorias para todos os tipos de mídia. O telejornalismo foi incluído somente a partir de $2001 .{ }^{1}$

O grande número de inscritos levou os organizadores a instituir, em 1994, um sistema de julgamento em duas instâncias. Uma comissão de seleção indica três trabalhos finalistas em cada categoria, que são avaliados, em uma segunda etapa, por uma comissão de premiação, responsável pelo resultado final do concurso. A exceção é a categoria de fotografia, na qual são indicados pela comissão de seleção os cinco melhores trabalhos. Uma comissão especial, formada por 50 jornalistas e editores de fotografia, tem como atribuição escolher o vencedor nesta categoria. As mudanças refletem um cenário completamente distinto em relação aos primeiros anos, quando havia uma única comissão, composta por apenas cinco membros (CASTILHO, 2008, p. 14).

\section{Conclusão}

A cultural profissional jornalística é largamente discutida na ciência e estudada em sua estrutura e conjunturas no que se refere à adoção (ou não) dos critérios de objetividade (Schudson, 1993; Hall et al., 1993). No entanto, esquece-se que os prêmios em Jornalismo são divulgadores de modelos, modalidades e tipologias jornalísticas. Sendo que certificam como vencedores, honoráveis, distintos e louváveis as práticas exemplares segundo um protocolo doutrinado do saber e do fazer jornalístico compartilhado neste ambiente: cultura profissional. Indiretamente, os definidores primários (HALL et al., 1993) acessam a cultura profissional a partir de uma cultura meritocrática premiativa reforçando uma investida direta às rotinas produtivas (TUCHMAN, 1993) na relação de fontes já conhecida e pacificada no processo de produção da notícia (MOLOTCH \& LESTER, 1993), perceptível na estruturação do Jornalismo Informativo e Jornalismo Investigativo a partir do Prêmio Pullitzer e Prêmio Esso, nas realidades dos EUA e Brasil, respectivamente. Nos EUA, quando os Rockfeller tentaram separar opinião de informação - de redação de assessorias, o que culminou na criação da profissão de Relações Públicas. No Brasil, a investida também dos Rockfeller em relação ao petróleo como recurso de energia a ser

1 www.premioesso.com.br, Linha do Tempo. Acesso em 20/08/2012.

$$
\text { Comunicação \& Inovação, PPGCOM/USCS }
$$


explorado pelos norte-americanos e da investida de mudança do noticiário da imprensa brasileira, até então nacionalista e antiamericana.

Falar em cultura meritocrática premiativa também é falar em elite profissional, pois os vencedores sempre são os jornalistas que contemplam o protocolo, a doutrina e a prática dita "exemplar" de quem promove o prêmio. E isto não está ligado apenas a chancelas de certificação, mas também a cursos de formação dentro desses modelos prescritos, pois são neles que se desenvolve uma nova geração a partir de um modelo jornalístico. A disputa pela paternidade dos cursos em Jornalismo, tanto nos EUA, quanto no Brasil, não têm referência pacífica exatamente pela disputa entre os polos do que seria o amador e o profissional. O bom e o mau exemplo, a partir de um modelo, de um protocolo. Isso é tão comum na cultura profissional, que a discussão sobre o verdadeiro aprendizado da profissão ser nos bancos das universidades ou no cotidiano do mercado não perde força e continua atual.

Neste breve artigo, o intuito foi apresentar este universo, não no sentido de esgotá-lo, mas de trazer novos elementos à questão de estruturação do que se entende por "profissional" e "objetividade" no Jornalismo, além dessa cultura meritocrática premiativa.

\section{Referências}

Armony, Flavio. Engajamento e Objetividade no Jornalismo Politico da França. (Dissertação, Mestrado em Comunicação), UFRJ. 2006

Barros Filho, Clóvis. Ética na comunicação. 4. ed. São Paulo: Summus, 1995.

Castilho, Marcio. "Um patrimônio dos próprios jornais" - as escolhas do campo jornalístico sob a ótica do Prêmio Esso. In: VII Encontro Nacional de História da Mídia, 2009, Fortaleza. VII Encontro Nacional de História da Mídia, 2009.

Diss, Robson. Prêmios em Jornalismo: paradigmas em transição. (Tese, Doutorado em Comunicação), UnB. 2013

Hall, Stuart, Chritcher, Chas, Jefferson, Tony et alii. A produção social das notícias: o "mugging” nos media". In: Traquina, Nelson. (Org.) Jornalismo: questões, teorias e estórias”. Lisboa, Vega, 1993

Hohlfeldt, L. Martino; V. França (orgs) - Teorias da Comunicação. Vozes. Petrópolis, 2001

Magno, Ana. A agonia da reportagem: das grandes aventuras da imprensa brasileira à crise do mais fascinante dos gêneros jornalísticos: uma análise das matérias vencedoras do Prêmio Esso de Jornalismo. (Dissertação, Mestrado em Comunicação, UnB). 2006

Medina, Cremilda. Profissão Jornalista: Responsabilidade Social. Rio de Janeiro. Forense. 1982.

Mendez, Rosemary. Pompeu de Sousa: jornalista, professor e político. Trabalho apresentado ao NP Intercom Jornalismo do VI Encontro dos Núcleos de Pesquisa em Comunicação. 2006

$136 \frac{\text { Comunicação \& Inovação, PPGCOM/USCS }}{\text { v. 15, n. } 29 \text { (126-137) jul-dez } 2014}$ 
Honra ao mérito: como a instituição do Prêmio Esso contribuiu para a adoção...

Molotch, Harvey e Lester Marilyn. As notícias como procedimento intencional: acerca do uso estratégico dos acontecimentos de rotina, acidentes e escândalos. In: Traquina, Nelson (org.) Jornalismo: Questões, teorias, estórias. Lisboa: Vega. p. 34-53.

Nascimento, Solano. Jornalismo sobre investigações: relações entre Ministério Público e a imprensa. (Tese, Doutorado em Comunicação). UnB. 2007.

Passos, Lucio. A Produção de Efeitos de Sentido nas Fotografias de Imprensa Brasileira: Análises Técnicas, Plásticas e Semânticas. (Dissertação, Mestrado em Comunicação), Universidade do Tuiuiú. 2007

PENA, Janis. Em busca da qualidade de vida individual do repórter: compreensão das mediações presentes no processo comunicacional dos jornalistas. (Tese, Doutorado em Comunicação), USP. 2006

SAnTANA, Wedencley. O discurso da notícia: objetivismo jornalístico e seus efeitos. (Dissertação, Mestrado em Comunicação), UFF. 2001.

SCHUDSOn, Michael, A política da forma narrativa: a emergência das convenções noticiosas na imprensa e na televisão. In: Traquina, Nelson. (Org.) Jornalismo: questões, teorias e “estórias”. Lisboa: Vega, 1993.

SoloskI, John. O jornalismo e o profissionalismo: alguns constrangimentos no trabalho jornalístico, in Traquina, Nelson. Jornalismo: questões, teorias e estórias'. Lisboa, Vega, 1993.

Traquina, Nelson (org). O estudo do jornalismo no século XX. São Leopoldo, RS: Ed. Unisinos, 2001. (org.). Jornalismo: Questões, teorias, estórias. Lisboa, Vega, 1999. (org.). A Tribo Jornalística: uma comunidade transnacional. Lisboa: Editorial Notícias, 2004a

Tuchman, Gaye. A objetividade como ritual estratégico: uma análise das noções de objetividade dos jornalistas, in Traquina, Nelson. Jornalismo: questões, teorias e estórias. Lisboa, Vega, 1993, P. 74-90. Wolf, Mauro. Teorias da comunicação. Lisboa: Ed. Presença, 1995. 